\title{
An Analysis of the Influence of Protective Films on the Inner Surfaces of CCPP Headers and Steam Pipelines on Their Thermal Stress State
}

\author{
Yury A. Radin, Tatiana S. Kontorovich \\ All-Russia Thermal Engineering Institute, Moscow, Russia \\ Email: vti-unit@yandex.ru
}

How to cite this paper: Radin, Yu.A. and Kontorovich, T.S. (2017) An Analysis of the Influence of Protective Films on the Inner Surfaces of CCPP Headers and Steam Pipelines on Their Thermal Stress State. American Journal of Analytical Chemistry, 8, 116124

http://dx.doi.org/10.4236/ajac.2017.81009

Received: November 4, 2016

Accepted: January 16, 2017

Published: January 19, 2017

Copyright $\odot 2017$ by authors and Scientific Research Publishing Inc. This work is licensed under the Creative Commons Attribution International License (CC BY 4.0).

http://creativecommons.org/licenses/by/4.0/

(c) (i) Open Access

\begin{abstract}
At present, the main attention of researchers is paid to the deterioration of heat transfer when heating the outer surface of the pipe with the liquid or steam, flowing inside it, in the presence of films or deposits on its inner surface. However, when pipe is heating by heat carrier medium, flowing inside it, film on the inner pipe surface serve a dual protective function, protecting the pipe from corrosion and reducing its thermal stress. The article represents the results of the computational analysis of protective films influence on the thermal stressed state of headers and steam pipelines of combined-cycle power plants (CCPP) heat-recovery steam generators at different transient operating conditions particularly at startups from different initial temperature states and thermal shock. It is shown that protective films have a significant influence on the stresses magnitude and damage accumulation mainly for great temperature disturbances (for thermal shock). Calculations were carried out at various thicknesses of films and assuming that their thermal conductivity less than thermal conductivity of the steam pipelines metal.
\end{abstract}

\section{Keywords}

Heat-Recovery Steam Generator, Header, Steam Pipeline, Protective Film, Stress, Thermal Shock, Startup, Equivalent Operating Hours

\section{Introduction}

Economizers and evaporators pipe systems, steam pipelines, attemperators and heat-recovery steam generator (HRSG) details experience cyclic impact of great and often drastic temperature changes of heat-transfer medium, leading to the fatigue damage accumulation, one of the most important kind of which is corrosion fatigue that is manifested in the metal destruction under the simultaneous 
action of cyclic stresses and corrosive environment [1] [2].

The measure of material corrosion fatigue strength is corrosion-mechanical strength, defined as the limit of the allowable static or cyclic stresses in the metal at the selected time interval or number of loading/unloading cycles.

On the one hand the cause of the rapid metal destruction is the oxide film destruction and on the other-metal surface damage, caused by corrosion, contributing to the fatigue cracks initiation. Under the influence of corrosion metal fatigue-limit is reduced in some cases by $65 \%$ against its normal value.

As a rule, damage from corrosion fatigue is greater than sum of damage, caused by fatigue and corrosion. Temperature fluctuations in the pipelines with steam or hot water, leading to their periodic expansion and compression, are the main types of damage and due to corrosion fatigue can cause destruction at stresses less than fatigue-limit [3].

The stress state of the detail is determined by stress intensity factor in the current point of the contour of the cracks at the time of its promotion. Equation (1) estimates stress intensity factor for plane strain:

$$
K I=\sigma \sqrt{\pi l /\left(1-v^{2}\right)}, \quad \mathrm{Pa} \cdot \mathrm{m}^{0,5},
$$

where $\sigma$ is the stress, $\mathrm{Pa} ; l$ is the crack length, $\mathrm{m} ; v$ is the Poisson's ratio. A protective (magnetite) film, able to regeneration, forms on the pipe-systems interior surface of combined-cycle power plants (CCPP) HRSG at temperatures over $230^{\circ} \mathrm{C}$ and good deaeration [4].

An oxide film or a corrosion products film, protecting the metal from corrosion environment, helps to prevent its corrosion-fatigue damage and also represents an additional thermal resistance in the heat exchange process between heat-transfer medium and metal. Low thermally conductive deposits and oxide films with high thermal resistance $(\delta / \lambda)=2.2 \times 10^{-4} \mathrm{~m}^{2} \cdot \mathrm{K} / \mathrm{W}$ [5] reduce the temperature of inner surface from the direction of heat-transfer medium.

\section{Description of the Calculation Model}

The mathematical model of the CCPP-450 high-pressure outlet superheater header $(426 \times 34 \mathrm{~mm})$ was used to analyze the films influence on the details of thermal stressed state. The calculation model was designed as a two-layer cylindrical shell whose inner layer was a protective film.

The modes with a stepped change of heat transfer medium temperature were considered, which usually are accompanied with the appearance of the highest stress. In these circumstances a film should reduce stresses in the base metal to the greatest degree.

The steam temperature was assumed to be constant and equal to $500^{\circ} \mathrm{C}$ at analysis of warm and hot startups and $400^{\circ} \mathrm{C}-500^{\circ} \mathrm{C}$ at analysis of cold startups. The initial metal temperature was assumed to be, respectively, $50^{\circ} \mathrm{C}$ at cold startups; $150^{\circ} \mathrm{C}$ at warm startups and $250^{\circ} \mathrm{C}$ at hot startups.

The calculations were performed by finite element method using ANSYS software. To assess the film effect on thermal stressed state of steam lines and 
headers, startup modes from different thermal states with aforementioned temperatures of steam and metal and heat transfer coefficient, changing with a constant velocity to a maximum value of $1500 \mathrm{~W} /\left(\mathrm{m}^{2} .^{\circ} \mathrm{C}\right)$ during $(0.5-15)$ minutes, were calculated.

Fatigue stress evaluation was carried out according to the method [6]. The thermal-stress concentration factor was taken equal to 2 .

\section{The Calculation Results Discussion}

Equation (2), which described the heat transfer through a multilayer cylindrical wall, is a good illustration of the mechanism of the film influence on the thermal stressed state of the base metal of cylindrical shell, although refers to the warm up mode with a constant heat flux density:

$$
q_{l}=\frac{\pi\left(t_{1}-t_{n+1}\right)}{\sum_{i=1}^{n} \frac{1}{2 \lambda_{i}} \ln \frac{d_{i+1}}{d_{i}}}
$$

where $q_{1}$ is the linear density of heat flux, $\mathrm{W} / \mathrm{m} ; t_{1}$ is the temperature of the inner surface of the multilayer wall, ${ }^{\circ} \mathrm{C}$; $t_{n+1}$ is the temperature of the outer surface of the $n$-layer wall, ${ }^{\circ} \mathrm{C} ; n=2$ is the number of layers; $\lambda_{i}$ is the thermal conductivity coefficient of the $i$-th layer, $\mathrm{W} / \mathrm{m} ; d_{i}$ is the inner diameter of the $i$-th layer, $\mathrm{m}$.

From Equation (2) it can be inferred that the temperature difference across the wall thickness of the base metal in the protective film presence is determined by the ratio of their thermal resistances $(\delta / \lambda)$.

Computation researches were carried out for films with thicknesses of 0.25 - 1 $\mathrm{mm}$. Protective film thermal conductivity was assumed to be half of the base metal thermal conductivity, which considerably exceeds the minimum value of thermal conductivity of iron oxides that form the protective film [6].

The results of calculations of modes like "thermal shock" equal to $100^{\circ} \mathrm{C}$ at initial metal temperature equal to $50^{\circ} \mathrm{C}$ and the heat transfer coefficient equal to $1500 \mathrm{~W} /\left(\mathrm{m}^{2} .^{\circ} \mathrm{C}\right)$ are represented as the relationship between temperature change across the wall thickness and the stress maximum from the protective film thickness (Figure 1 and Figure 2).

As it follows from carried out calculations, the film presence on the surface, contacts with heat transfer medium, reduces temperature on the base metal surface and thus reduces stress in it. The greatest effect of the film presence occurs under "thermal shock" mode at the first moment of temperature action, when only the boundary layer has time to heat, the major part of which is film (Figure 1). The maximum stresses occur in the base metal 21 - 24 seconds later. By that time there is a partial alignment of the temperature field in the wall, and the effect of the film presence is reduced. At a quasi-stationary mode the wall temperature field is established from the very beginning of heating process, so the effect of the film presence obviously will be significantly less.

Figure 3 shows the dependence of the temperature difference across the wall thickness of the base metal of the header from the rate of HRSG capacity rise, taking into account the protective film presence. As can be seen from this figure, 


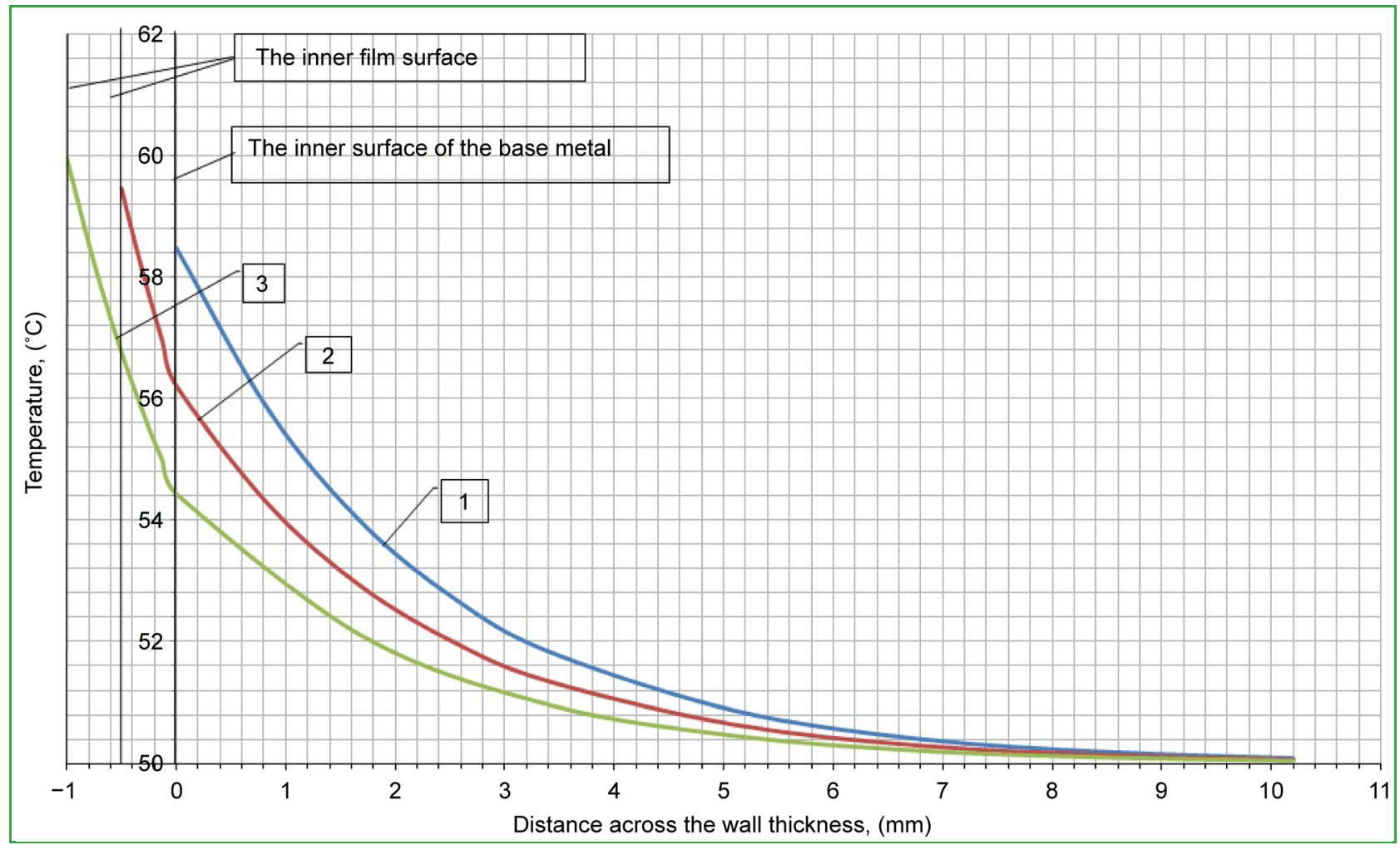

Figure 1. The temperature distribution across the wall thickness in "thermal shock" mode $0.5 \mathrm{~s}$ after the heating start for different protective film thickness. (1) Protective film is absent; (2) Protective film thickness is $0.5 \mathrm{~mm}$; (3) Protective film thickness is 1 $\mathrm{mm}$.

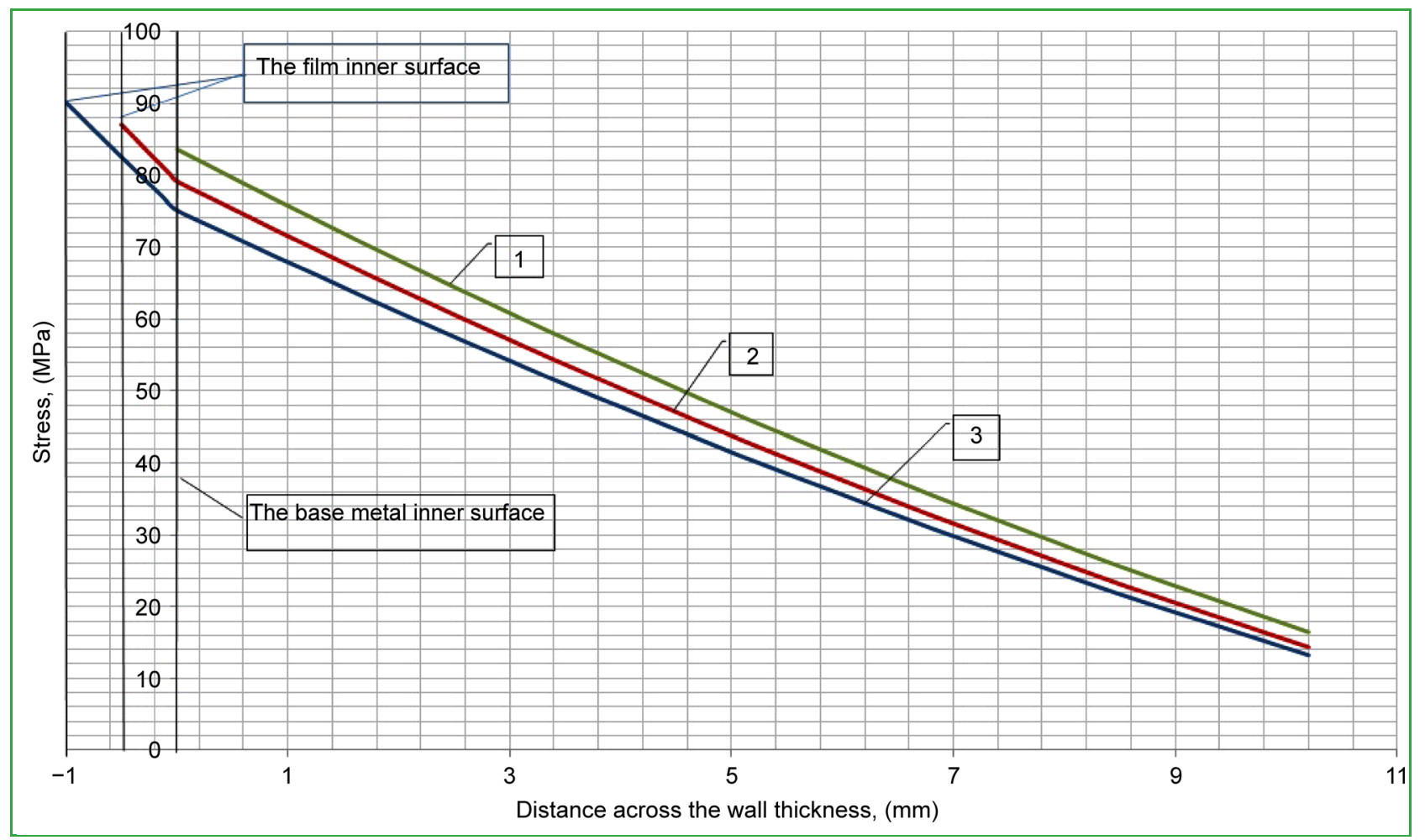

Figure 2. The distribution of equivalent stress maximum across the wall thickness for different protective films thicknesses. (1) Protective film is absent; (2) Protective film thickness is $0.5 \mathrm{~mm}$; (3) Protective film thickness is $1 \mathrm{~mm}$. 


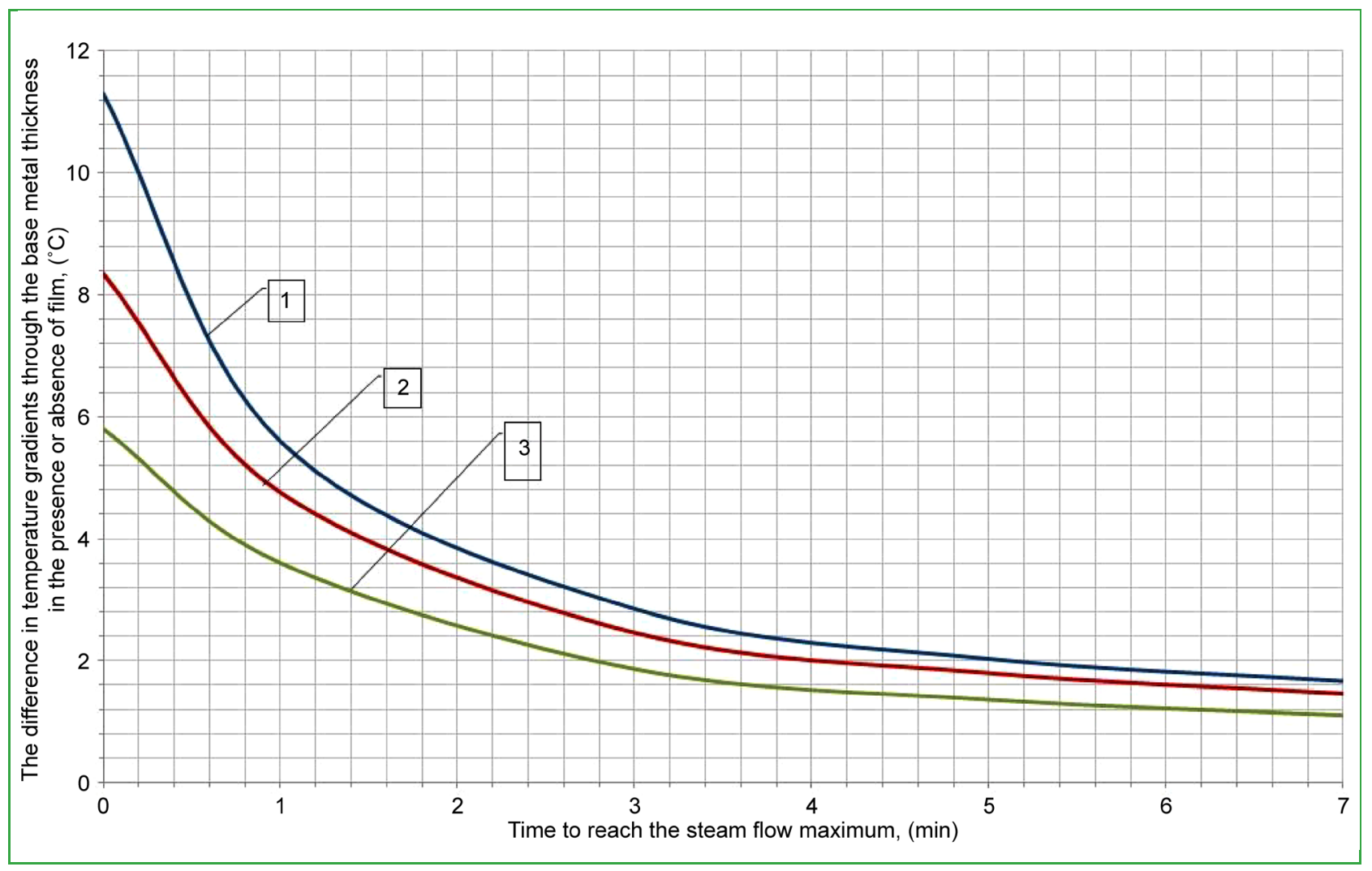

Figure 3. The film influence on the temperature difference across the thickness of the base metal wall of the header $426 \times 34 \mathrm{~mm}$ when starting from different thermal states. (1) Cold start; (2) warm start; (3) hot start.

due to the film presence, the temperature difference is reduced in a greatest extent during cold startup with initial steam temperature equal to $500^{\circ} \mathrm{C}$ at the maximum rate of steam flow increase.

Figure 3 shows the dependence of the temperature difference across the wall thickness of the base metal of the header from the rate of HRSG capacity rise, taking into account the protective film presence. As can be seen from this figure, due to the film presence, the temperature difference is reduced in a greatest extent during cold startup with initial steam temperature equal to $500^{\circ} \mathrm{C}$ at the maximum rate of steam flow increase.

The effect of the film on the temperature difference across the wall thickness affects only during fast startups, reaching the value of $11^{\circ} \mathrm{C}$ at cold startup, when the maximum steam flow is reached in a minute after startup beginning. At a lower loading rate, when the nominal steam flow is achieved not earlier than 5 minutes after the start the change of the temperature difference across the header wall thickness the regardless of the film presence and the type of startup doesn't exceed $2^{\circ} \mathrm{C}$.

The corresponding stress reduction due to the film presence at cold startup with an initial steam temperature of $400^{\circ} \mathrm{C}$ is $13-15 \mathrm{MPa}$, at an initial steam temperature of $500^{\circ} \mathrm{C}-17.4 \mathrm{MPa}$.

These values refer to startup at such loading rate, that a given steam flow is achieved in a minute after the start. 
Similarly, there is a decrease of equivalent operating hours, accumulated at one startup, reaching 47.7 at cold startup with the initial steam temperature of $500^{\circ} \mathrm{C}$ (Figure 4). At a lower loading rate, when the nominal steam flow is achieved not earlier than in 5 minutes, the effect of the application of the protective film is about 7 equivalent operating hours.

The calculation of equivalent operating hours was carried out according to the methodology described in [7].

At warm startups the difference in the number of equivalent operating hours accumulated for a single startup varies from 36 to 4 under the same conditions. At hot startups the protective films have a noticeable effect only at startups at rated steam parameters and it is about 15.2 equivalent operating hours.

The gain in the accumulation of equivalent operating hours when applying film is determined by its thickness, and as can be seen from Figure 5, this functional connection is linear.

The maximum decrease in equivalent operating hours, accumulated for a single startup, through the use of film corresponds to the "thermal shock" mode, i.e. in this case, the mode, in which steam flow has a maximum value from the very startup beginning.

Calculations have shown that the film, having a layer of relatively high thermal resistance at the boundary with metal wall, reduces stress in the wall of

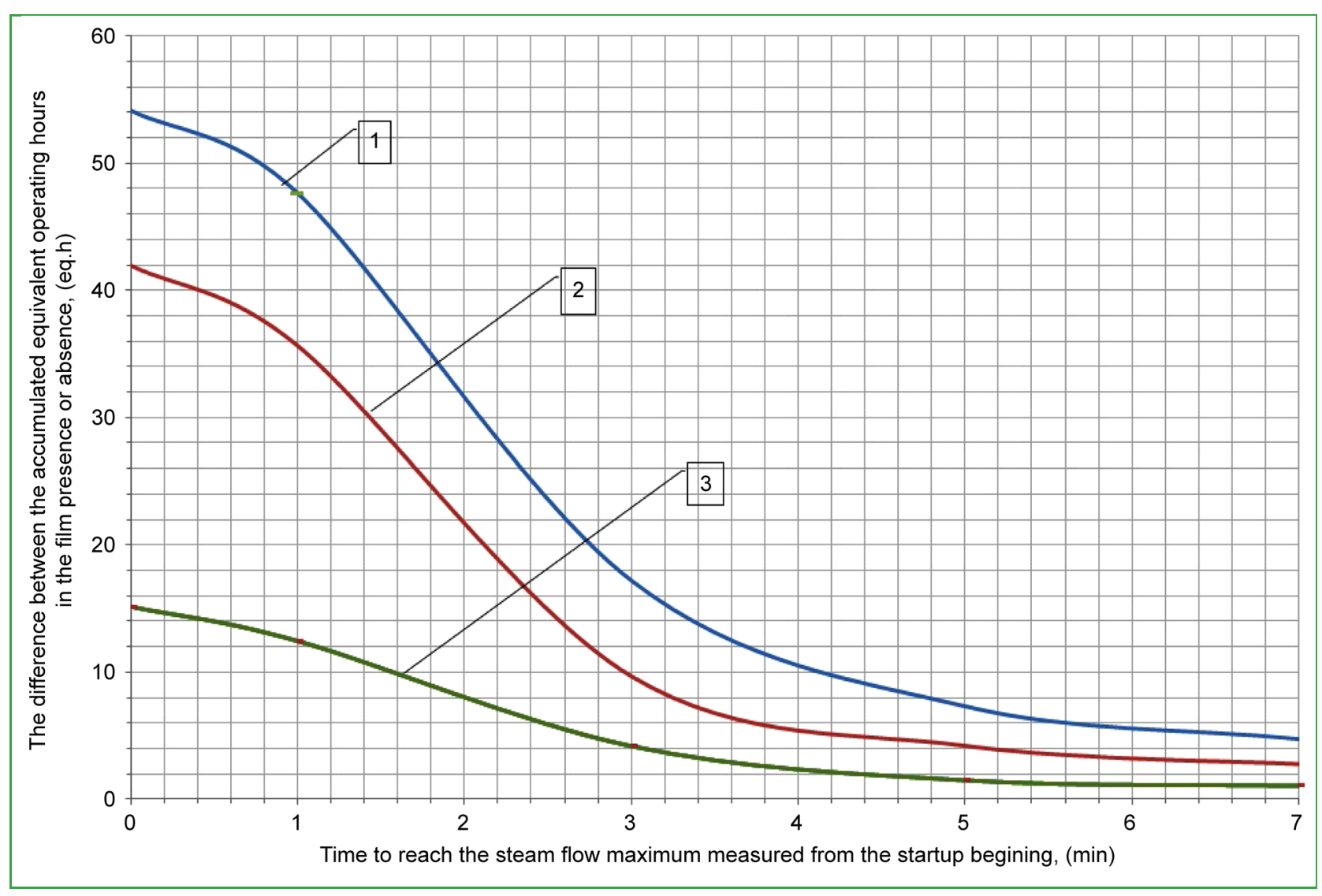

Figure 4. The film influence on the equivalent operating hours, accumulated for a single startup, at startups from different thermal states. (1) Cold startup; (2) warm startup; (3) hot startup. 


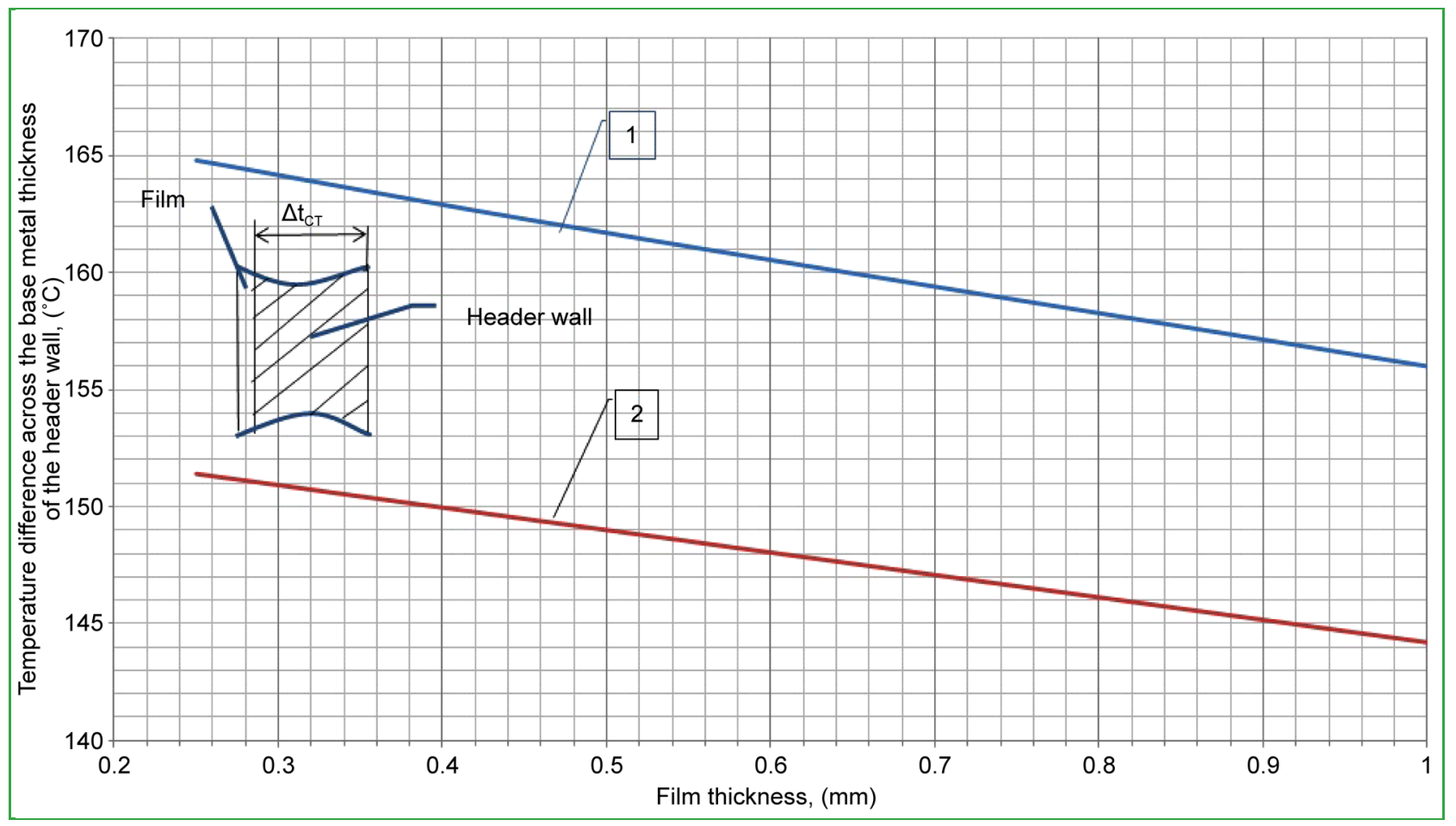

Figure 5. Film thickness influence on the temperature difference across the thickness of the base metal wall of the header $426 \times 34$ $\mathrm{mm}$ at a cold startup with initial steam temperature to $500^{\circ} \mathrm{C}$. (1) Maximum temperature difference across the wall thickness, in the case when the maximum flow rate is achieved immediately after startup beginning; (2) Maximum temperature difference across the wall thickness, in the case when the maximum flow rate is achieved in a minute after startup beginning.

header and the number of equivalent operating hours, accumulated in a single startup the most effectively (Figure 6).

For multilayer films under stationary process it follows from the Equation (3):

$$
\bar{\lambda}=\frac{\sum_{i=1}^{n} \frac{1}{\lambda_{i}} \ln \frac{d_{i+1}}{d_{i}}}{\frac{1}{\lambda} \ln \frac{d_{\text {out }}}{d_{\text {in }}}},
$$

where $\bar{\lambda}$ is the ratio of the thermal resistance of the film to the thermal resistance of the wall, $n$ is the number of the film layers with different thermal conductivities, $d_{i+1}, d_{i}$ are outer and inner diameters of the $i$-th film layer, $\mathrm{m} ; \lambda_{i}$ is the $i$-th film layer conductivity, $\mathrm{W} /\left(\mathrm{m} \cdot{ }^{\circ} \mathrm{C}\right) ; \lambda$ is the thermal conductivity of the wall material; $d_{o u}, d_{\text {in }}$ are the outer and the inner diameters of the header wall, $\mathrm{m}$.

Reducing the number of equivalent operating hours, accumulated over a cold startup, is 4.4 equivalent operating hours for the film with a thickness of $0.5 \mathrm{~mm}$, provided that maximum value of the heat transfer coefficient is achieved in a minute after startup beginning and 6.3 equivalent operating hours if the heat transfer coefficient had a maximum value at the very beginning of the startup.

Thus the reduction of the number of equivalent operating hours, accumulated by CCPP high pressure (HP) superheater header for a service life of 200000 hours and 2000 cold startups will be $4.4 \%-6.3 \%$ for a film thickness of $0.5 \mathrm{~mm}$ and $9.1 \%-13.2 \%$ for a film thickness of $1 \mathrm{~mm}$. 


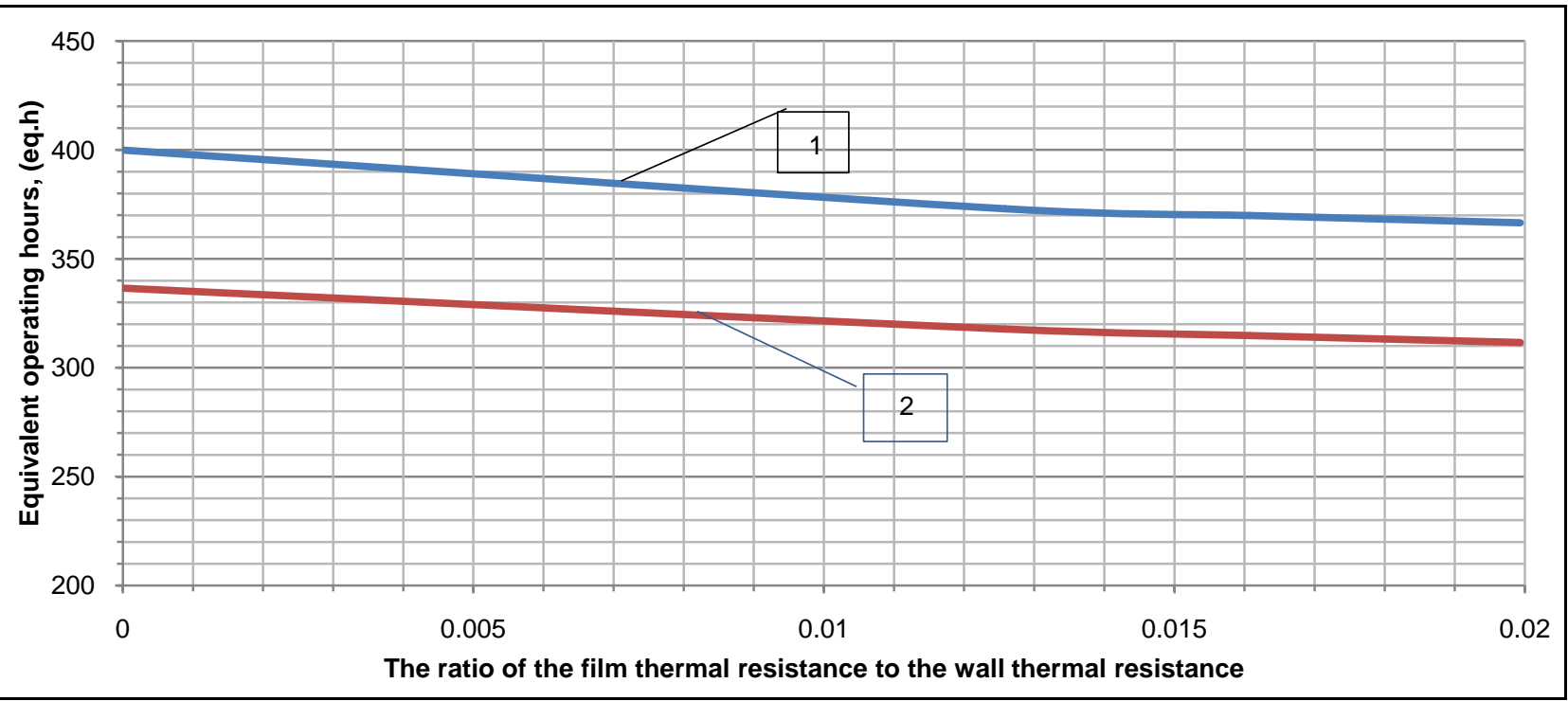

Figure 6. Influence of the film thermal resistance on the number of equivalent operating hours, accumulated during a single startup. (1) Maximum flow rate is achieved immediately after startup beginning; (2) Maximum flow rate is achieved in a minute after startup beginning.

\section{Conclusions}

1) Analysis of the results of thermal stress state calculations of the header with and without considering the influence of a protective film on its inner surface allows to draw the following conclusions about its impact on the thermal stress state and cyclic strength:

a) Protective films formed on the inner surface of the HRSG pipeline systems not only protect metal from corrosion attack occurring from internal steam flow, but also enhance its thermal and cyclic strength, reduce the number of equivalent operating hours, accumulated over a single transient mode.

b) The film influence on the thermal state and cyclic strength of steam pipelines and headers is the most evident in the modes with a step change in steam temperature, for example "heat shock", under condensation, and among startups from different thermal states-when cold startup. At a quasi-stationary mode and at hot startups the impact of the film is minimal.

c) As a rule, the resource of high pressure superheater header of CCPP is 200,000 hours. If it is assumed that during this period the number of cold startups will be 2000, then the presence of protective oxide film of $0.05 \mathrm{~mm}$ thickness on the inner surface of the header $426 \times 34 \mathrm{~mm}$ will reduce the number of accumulated equivalent operating hours by $4.4 \%-6.3 \%$ depending on the steam flow. For larger film thicknesses the reduction of the accumulated equivalent hours may be increased to $9.1 \%-13.2 \%$.

2) Prospects for using the results of this work in the future are related to the analysis protected films or coatings proper with the desired heat-transfer properties and technology of their application to the header inner surface. Application of such a protection would enhance the cyclical strength by reducing the damage of heavy loaded elements of CCPP steam water path. 


\section{References}

[1] Bogachev, A.F., Radin, Yu.A. and Gerasimenko, O.B. (2008) Operation Special Aspects and Damage of Binary Combined-Cycle Power Plants Heat Recovery Steam Generators. Energoatomizdat, Moscow.

[2] Dooley, B.R. and Tilley, R. (2004) Tube Failures in Conventional Fossil Fired Boiler and in Combined Cycle HRSG's. Power Plant Chemistry, 6, 14-21.

[3] Conference International (2004) Boiler Tube and Tube Failure and Inspections Proceedings of the International conference. Power Plant Chemistry, 6, 708-716.

[4] Antikajn, P.A. (1990) Metals and Strength Calculation of Boilers and Piping. Energoatomizdat, Moscow.

[5] Mankina, N.N. (1977) Physical and Chemical Processes in the Power Plants SteamWater Cycle. Energy, Moscow.

[6] RD (Guiding Document) 10-249-98 (2004) Regulations for Strength Design of Stationary Boilers and Steam and Hot-Water Pipelines. Gosgortekhnadzor, Moscow.

[7] Radin, Yu.A. and Kontorovich, T.S. (2012) applying the Equivalent Operating Hours Principle for Estimating the Reliability of Combined-Cycle Power Plant Equipment. Electric Generating Stations, 1, 16-18.

\section{Submit or recommend next manuscript to SCIRP and we will provide best} service for you:

Accepting pre-submission inquiries through Email, Facebook, LinkedIn, Twitter, etc. A wide selection of journals (inclusive of 9 subjects, more than 200 journals)

Providing 24-hour high-quality service

User-friendly online submission system

Fair and swift peer-review system

Efficient typesetting and proofreading procedure

Display of the result of downloads and visits, as well as the number of cited articles

Maximum dissemination of your research work

Submit your manuscript at: http://papersubmission.scirp.org/

Or contact ajac@scirp.org 